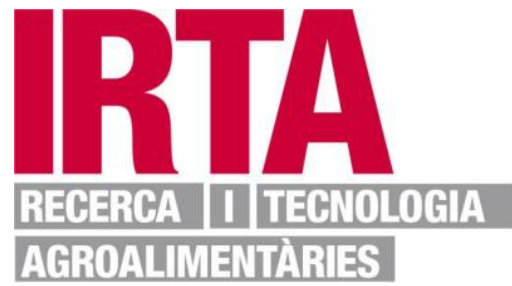

This is the peer reviewed version of the following article: Xoaquín Moreira, Luis Abdala-Roberts, Jorge C. Berny Mier y Teran, Felisa Covelo, Raúl de la Mata, Marta Francisco, Bess Hardwick, Ricardo Matheus Pires, Tomas Roslin, Dmitry S. Schigel, Jan P. J. G. ten Hoopen, Bart G. H. Timmermans, Laura J. A. Van Dijk, Bastien Castagneyrol and Ayco J. M. Tack. 2019. "Impacts of urbanization on insect herbivory and plant defences in oak trees". Oikos 128: 113-123, 2019. Wiley. doi: 10.1111/oik.05497. which has been published in final form at https://doi.org/10.1111/oik.05497. This article may be used for non-commercial purposes in accordance with Wiley Terms and Conditionsfor Use of Self-Archived Versions 


\section{Impacts of urbanization on insect herbivory and plant defences in oak trees}

Xoaquín Moreira ${ }^{1}$, Luis Abdala-Roberts ${ }^{2}$, Jorge C. Berny Mier y Teran ${ }^{3}$, Felisa Covelo ${ }^{4}$, Raúl de la Mata ${ }^{5}$, Marta Francisco ${ }^{1}$, Bess Hardwick ${ }^{6}$, Ricardo Matheus Pires ${ }^{8}$, Tomas Roslin ${ }^{6,7}$, Dmitry S. Schigel ${ }^{9}$, Jan P. J. G. ten Hoopen ${ }^{10}$, Bart G. H. Timmermans ${ }^{11}$, Laura J. A. van Dijk ${ }^{12}$, Bastien Castagneyrol ${ }^{13}$ and Ayco J. M. Tack ${ }^{12}$

${ }^{1}$ Misión Biológica de Galicia (MBG-CSIC), Apdo. 28, ES-36080 Pontevedra, Galicia, Spain ${ }^{2}$ Depto de Ecología Tropical, Campus de Ciencias Biológicas y Agropecuarias, Univ. Autónoma de Yucatán, Mérida, Yucatán, México

${ }^{3}$ Dept of Plant Sciences, Univ. of California-Davis, Davis, CA, USA

${ }^{4}$ Depto de Sistemas Físicos, Químicos y Naturales, Univ. Pablo de Olavide, Sevilla, Spain

${ }^{5}$ Research Inst. of Food Technology and Agriculture-IRTA, Caldes de Montbui, Spain

${ }^{6}$ Dept of Agricultural Sciences, Univ. of Helsinki, Helsinki, Finland

${ }^{7}$ Dept of Ecology, Swedish Univ. of Agricultural Sciences, Uppsala, Sweden

${ }^{8}$ Inst. de Botânica de São Paulo, Núcleo de Pesquisa em Micologia, São Paulo, SP, Brasil

${ }^{9}$ Dept of Biosciences, Faculty of Biological and Environmental Sciences, Univ. of Helsinki, Helsinki, Finland

${ }^{10}$ OneNature Ecology, Arnhem, the Netherlands

${ }^{11}$ Louis Bolk Inst., Bunnik, the Netherlands

${ }^{12}$ Dept of Ecology, Environment and Plant Sciences, Stockholm Univ., Stockholm, Sweden

${ }^{13}$ BIOGECO, INRA, Univ. Bordeaux, Cestas, France

Corresponding author: Xoaquín Moreira, Misión Biológica de Galicia (MBG-CSIC), Apdo.

28, ES-36080 Pontevedra, Galicia, Spain. E-mail: xmoreira1 @ gmail.com

Decision date: 13-Jul-2018

This article has been accepted for publication and undergone full peer review but has not been through the copyediting, typesetting, pagination and proofreading process, which may lead to differences between this version and the Version of Record. Please cite this article as doi: [10.1111/oik.05497]. 


\section{(ABSTRACT)}

Systematic comparisons of species interactions in urban $v s$. rural environments can improve our understanding of shifts in ecological processes due to urbanization. However, such studies are relatively uncommon and the mechanisms driving urbanization effects on species interactions (e.g. between plants and insect herbivores) remain elusive. Here we investigated the effects of urbanization on leaf herbivory by insect chewers and miners associated with the English oak Quercus robur by sampling trees in rural and urban areas throughout most of the latitudinal distribution of this species. In performing these comparisons, we also controlled for the size of the urban areas (18 cities) and gathered data on $\mathrm{CO}_{2}$ emissions. In addition, we assessed whether urbanization affected leaf chemical defences (phenolic compounds) and nutritional traits (phosphorus and nitrogen), and whether such changes correlated with herbivory levels. Urbanization significantly reduced leaf chewer damage but did not affect leaf miners. In addition, we found that leaves from urban locations had lower levels of chemical defences (condensed and hydrolysable tannins) and higher levels of nutrients (nitrogen and phosphorus) compared to leaves in rural locations. The magnitude of urbanization effects on herbivory and leaf defences was not contingent upon city size. Importantly, while the effects of urbanization on chemical defences were associated with $\mathrm{CO}_{2}$ emissions, changes in leaf chewer damage were not associated with either leaf traits or $\mathrm{CO}_{2}$ levels. These results suggest that effects of urbanization on herbivory occur through mechanisms other than changes in the plant traits measured here. Overall, our simultaneous assessment of insect herbivory, plant traits and abiotic correlates advances our understanding of the main drivers of urbanization effects on plant-herbivore interactions.

Keywords: chemical defences, city size, leaf chewers, leaf miners, nutrients, Quercus robur, rural, urban 


\section{INTRODUCTION}

Urban landscapes now occupy a major fraction of the globe, and are expected to further increase in area during this century (United Nations Department of Economics and Social Affairs 2014). Urbanization produces abrupt and strong changes in the local biotic or abiotic environment, which influence remnant or restored ecological communities found within urban areas (McDonnell and Pickett 1990, McDonnell et al. 1997, Johnson and Munshi-South 2017). For instance, urbanization often results in local increases in temperature and $\mathrm{CO}_{2}$ levels, as well as in changes in soil water or nutrient availability (Johnson and Munshi-South 2017). Such changes in turn directly or indirectly influence plant and animal species and the outcome of their interactions (Hahs et al. 2009, Lambert et al. 2015, El-Sabaawi 2018). Within this context, recent work has focused on describing the effects of urbanization on broad descriptors of plant and animal communities (e.g., diversity and species composition) by comparing urban $v s$. rural habitats or urban-rural gradients (reviewed by Beninde et al. 2015). However, comparatively less work has focused on evaluating the impact of urbanization on species interactions (but see Turrini et al. 2016, Kozlov et al. 2017). This gap limits our understanding of how urbanization alters the function of ecological communities as well as our ability to design more sustainable and environment-friendly urban environments.

Overall, plant-herbivore interactions represent one of the most widespread and dominant ecological interactions on our planet, with the two species groups accounting for most of the species and biomass on the planet (Carmona et al. 2011). Plantherbivore interactions also play a pivotal role in ecosystem functioning (Stam et al. 2014, Turcotte et al. 2014). Nonetheless, studies on herbivory, particularly by insects, in urban settings or along transitions between urban and rural environments have received relatively little attention (Dreistadt et al. 1990, Raupp et al. 2010). In addition, the few 
studies conducted over the last two decades have reported contrasting patterns of insect herbivory on trees and herbaceous plants; some studies have reported higher insect herbivory in urban areas relative to rural habitats (e.g., Cuevas-Reyes et al. 2013, Turrini et al. 2016) whereas other studies have found the opposite pattern (e.g., Bode and Gilbert 2016, Kozlov et al. 2017). Unfortunately, the causes behind these patterns are not always clear (Raupp et al. 2010). Further work on the underlying ecological factors driving urbanization effects on insect herbivory is needed to understand the mechanisms behind changes in species interactions and ecological function in urban environments.

Most previous studies have directly evaluated the effect of urbanization on insect diversity or abundance, and seldom explored the abiotic or biotic factors that may drive these direct or indirect urbanization effects (Raupp et al. 2010). However, apart from any direct effects of urbanization on insect herbivory, regulatory processes could be indirectly mediated by changes in plant traits such as chemical defences and nutritional quality (Thompson et al. 2016) or by changes in predation pressure on herbivore populations (Burkman and Gardiner 2014, Turrini et al. 2016, Kozlov et al. 2017). Accordingly, information on shifts in the relative strength of bottom-up and top-down effects on herbivore populations in urban vs. rural environments is needed to better explain changes in species interactions due to urbanization. Similarly, we know that urbanization causes changes in the relative abundance and species composition of insect herbivore communities (Herrmann et al. 2012), and such changes are likely to influence the amount and type damage (Kozlov et al. 2017). Yet few studies have reported separate measures of damage caused by different herbivore species or guilds (but see Kozlov et al. 2017). In addition, abiotic factors presumably underlie effects of urbanization on plant-herbivore interactions but are usually not accounted for (Turrini et 
al. 2016). This limitation is of key importance, since abiotic correlates of urbanization such as $\mathrm{CO}_{2}$ emissions or temperature can influence both plants and insects (Zvereva and Kozlov 2006, Stiling and Cornelissen 2007, Robinson et al. 2012, Searle et al. 2012, Youngsteadt et al. 2015), and are therefore likely to play an important part in mediating direct and indirect effects of urbanization on herbivory (Thompson et al. 2016). Finally, in considering the effects of biotic or abiotic factors, it is important to control for other landscape-level aspects associated with urban areas, such as city size, area, or vegetation cover (Youngsteadt et al. 2015, Kozlov et al. 2017). Such features may alter both direct and indirect mechanisms influencing herbivory.

In this study, we investigated the effects of urbanization on insect herbivory associated with the English oak Quercus robur L. (Fagaceae). We compared damage on oak trees in urban $v s$. adjacent rural areas spanning most of the distribution of this species in Western Europe (across $19^{\circ}$ latitude and $33^{\circ}$ longitude). In addition, we also controlled for city size by sampling urban areas of different population size (18 cities, Fig. 1). To assess the potential causes behind patterns of herbivory, we further measured leaf damage by two insect feeding guilds (leaf miners and chewers), leaf chemical defences (multiple groups of phenolic compounds) and nutritional traits (phosphorus and nitrogen), and obtained data on $\mathrm{CO}_{2}$ emissions. In doing so, we sought to answer the following questions: (1) Does urbanization affect insect herbivory and plant traits, and is the magnitude of such effect contingent upon city size? (2) Does urbanization have similar effects on damage by both guilds of insect herbivores or are there guildspecific patterns? And (3) are effects of urbanization on herbivory associated with changes in leaf traits (chemical defences and nutrients), and do abiotic factors $\left(\mathrm{CO}_{2}\right.$ emissions) mediate urbanization effects on leaf traits and insect damage? In addressing the associations, it is important to consider that the effect of urbanization may operate in 
different ways: (i) urbanization could drive changes in plant traits which in turn influence herbivory, (ii) urbanization could drive insects and herbivory which in turn influences leaf defences (i.e., via differences in plant induction), (iii) urbanization could affect herbivory and leaf traits independently (as evidenced by the absence of a relationship between the effects of urbanization on herbivory and leaf traits). Overall, this work provides a robust assessment of effects of urbanization on plant-herbivore interactions, and uniquely addresses the factors or mechanisms underlying such effects.

\section{MATERIAL AND METHODS}

\section{Natural history}

The English oak, Quercus robur, offers an ideal species for measuring effects of urbanization on plant-herbivore interactions, since it has a broad geographic distribution, sustains a diverse community of associated insects, and is present in high densities both in rural and urban environments throughout Western Europe. Overall, $Q$. robur is distributed from northern Portugal $\left(40^{\circ} \mathrm{N}\right)$ to southern Finland $\left(61^{\circ} \mathrm{N}\right)$, across a wide range of climatic conditions (Petit et al. 2002). Individual trees are long-lived, up to 200 years. Leaf burst in this deciduous species usually occurs during April in southern Europe and in May for northern Europe, whereas leaf senescence and leaf drop typically start in September for northern Europe and in October for southern Europe. In its native range, $Q$. robur supports a diverse community of specialist (and a few generalist) insect herbivores such as leaf chewers, miners and gallers (Southwood et al. 2005, Tack et al. 2010, Tack and Roslin 2011, Castagneyrol et al. 2012, Giffard et al. 2012, Moreira et al. 2017, 2018).

\section{Study sites}


For this study, we selected 18 European cities (in six countries; i.e., three cities per country) varying in population size (small: 21,000-46,000 inhabitants; medium-sized: 152,000-292,000 inhabitants; large: >1,000,000 inhabitants), spanning $19^{\circ}$ in latitude (from $41^{\circ} \mathrm{N}$ to $60^{\circ} \mathrm{N}$, Fig. 1). Associated to each city, we selected one urban and one rural sampling location (Kozlov et al. 2017). The experiment followed a split-plot design replicated in six blocks (i.e., countries), with city population size (three levels: large, medium and small) as the whole plot factor and urbanization (urban or rural locations) as the split factor. Urban locations included streets, parks and small gardens as close to the city centre as possible, whereas rural locations were represented by stands of natural forest located 10-80 km from the city limits (Kozlov et al. 2017). From north to south across sampling locations, trees and herbivores experience over a three-fold increase in mean annual precipitation (518 to $1,630 \mathrm{~mm}$ ) and an increase of $11.2^{\circ} \mathrm{C}$ in mean annual temperature (from $4.6^{\circ} \mathrm{C}$ to $15.8^{\circ} \mathrm{C}$ ), covering most of the latitudinal and climatic gradients experienced by this tree species throughout its distribution range (Moreira et al. 2018).

\section{Field sampling and leaf herbivory measurements}

We sampled plants at the end of the growing season of each site, i.e., late August to early September at the northernmost sites and from late September to early October at the southernmost sites. This procedure minimized phenological differences in herbivory and plant defensive traits among sites (Moreira et al. 2018). In addition, sampling plants at the end of the growing season offers two advantages: it provides an assessment of cumulative leaf herbivory occurring over the entire growing season and it is the time of year when oak leaf herbivory and chemistry are relatively stable (Salminen et al. 2004). To estimate herbivory, we randomly selected five individuals per site. For each 
tree, we randomly selected two low-hanging branches (2-3 $\mathrm{m}$ from the ground) and collected 25 leaves from each branch. Leaves measured at our study sites were mostly damaged by insect chewers and miners (X. Moreira, personal observastion). For each leaf, we visually estimated percent leaf area removed by leaf chewers using the following scale: $0=$ undamaged; $1=1-5 \%$ damaged; $2=6-10 \%$ damaged; $3=11-25 \%$ damaged; $4=26-50 \%$ damaged; $5=51-75 \%$ damaged; $6=>75 \%$ damaged) ("leaf chewer damage" hereafter) (Castagneyrol et al. 2013), and then averaged values across all leaves to obtain mean values per tree. In addition, we counted mines on each leaf and estimated the number of mines per 25 leaves for each branch ("leaf miner abundance" hereafter). Then we averaged values across branches to obtain a mean value per tree for statistical analyses. To avoid biases in our herbivory estimates, the same person (XM) scored all the leaves during the entire study.

For chemical analyses, we collected four fully expanded (mature) leaves per tree. We only collected leaves with little or no herbivore damage in order to minimize variation in defence levels caused by site-specific induction (Abdala-Roberts et al. 2016a). However, there may still be systemic induced responses that are not accounted for with this procedure, and therefore measured levels of chemical defences presumably represented a combination of constitutive defences, plus an unknown level of systemic induction (Abdala-Roberts et al. 2016a). After collection, we oven-dried leaves for $48 \mathrm{~h}$ at $40^{\circ} \mathrm{C}$, ground them with liquid nitrogen, and stored the samples for subsequent quantification of phenolic compounds and nutrients. Leaves from each tree were pooled into a single sample for chemical analyses.

\section{Quantification of phenolic compounds}

We chose phenolic compounds as defensive traits because they are widely recognized as 
herbivore feeding deterrents across many plant taxa (Mithöfer and Boland 2008, Salminen and Karonen 2011), and because they have been previously shown to confer resistance against leaf herbivores in Q. robur (Feeny 1970, Roslin and Salminen 2008, Abdala-Roberts et al. 2016b, Moreira et al. 2017, 2018). We extracted phenolic compounds using $20 \mathrm{mg}$ of dry plant tissue with $1 \mathrm{~mL}$ of $70 \%$ methanol in an ultrasonic bath for $15 \mathrm{~min}$, followed by centrifugation (Moreira et al. 2014). We then transferred these methanolic extracts to chromatographic vials to perform the chromatographic analyses. Chromatographic analyses were carried out using an Ultra-High-Performance Liquid-Chromatograph (UHPLC Nexera LC-30AD; Shimadzu) equipped with a Nexera SIL-30AC injector and one SPD-M20A UV/VIS photodiode array detector. The UHPLC column was a Kinetex ${ }^{\mathrm{TM}} 2.6 \mu \mathrm{m}$ C18 82-102 Å, LC Column $100 \times 4.6$ mm, protected with a $\mathrm{C} 18$ guard cartridge. The flow rate was $0.4 \mathrm{~mL} \mathrm{~min}^{-1}$ and the oven temperature was set at $25^{\circ} \mathrm{C}$. The mobile phase consisted of two solvents: water-formic acid $(0.05 \%)(\mathrm{A})$ and acetonitrile-formic acid (0.05\%) (B), starting with 5\% B and using a gradient to obtain $30 \% \mathrm{~B}$ at $4 \mathrm{~min}, 60 \% \mathrm{~B}$ at $10 \mathrm{~min}, 80 \% \mathrm{~B}$ at $13 \mathrm{~min}$ and $100 \% \mathrm{~B}$ at $15 \mathrm{~min}$. The injection volume was $30 \mu \mathrm{L}$. We recorded chromatograms at $330 \mathrm{~nm}$ and processed data on a computer with the LabSolutions software (Shimadzu). We quantified flavonoids as rutin equivalents, condensed tannins as catechin equivalents, hydrolysable tannins as gallic acid equivalents, and lignins as ferulic acid equivalents. We achieved the quantification of these phenolic compounds by external calibration using calibration curves at $0.25,0.5,1,2$ and $5 \mu \mathrm{g} \mathrm{mL} \mathrm{m}^{-1}$. Phenolic compound concentrations were expressed in $\mathrm{mg} \mathrm{g}^{-1}$ tissue on a dry weight basis.

\section{Quantification of nutrients}

We chose phosphorus and nitrogen as proxies for leaf nutrient status because these 
macro-nutrients are typically found in low concentrations in plant tissues across many plant taxa and are therefore assumed to be limiting relative to herbivore nutritional requirements (Mattson 1980). Accordingly, they are frequently strongly correlated with levels of leaf herbivory (Mattson 1980, Huberty and Denno 2006), a pattern that has previously been reported for several oak species (e.g., Forkner and Hunter 2000, Abdala-Roberts et al. 2016b, Moreira et al. 2018). To quantify leaf nutrient concentrations, we digested approximately $0.1 \mathrm{~g}$ of ground dried leaf material in a mixture of selenous sulphuric acid and hydrogen peroxide (Moreira et al. 2012). We then used a colorimetric analysis of diluted aliquots of the digestion to quantify nitrogen (indophenol blue method) and phosphorus (molybdenum blue method) concentration using a Biorad 650 microplate reader (Bio-Rad Laboratories, Philadelphia, PA, USA) at $650 \mathrm{~nm}$ and $700 \mathrm{~nm}$, respectively (Walinga et al. 1995). Nitrogen and phosphorus concentrations were expressed in $\mathrm{mg} \mathrm{g}^{-1}$ dry tissue.

\section{Geographic and abiotic factors}

We obtained the geographic coordinates of each $Q$. robur site using a Global Positioning System device (Garmin, Kansas, USA). We obtained the anthropogenic $\mathrm{CO}_{2}$ emissions of each site from the ODIAC2017 fossil fuel $\mathrm{CO}_{2}$ emission dataset (http://db.cger.nies.go.jp/dataset/ODIAC/) at $1 \mathrm{~km}$ resolution. We used the average yearly $\mathrm{CO}_{2}$ emissions from 2007 to 2016 for the statistical analyses (mean value for urban areas: $1406.8 \pm 310.6 \mathrm{PgC}$, mean value for rural areas: $241.0 \pm 93.4 \mathrm{PgC})$. The procedure to calculate this variable is described at Oda et al. (2018). We did not account for climatic variables in our analyses because we lacked direct measurements of temperature changes in urban areas (i.e., urban heat islands) and rainfall patterns are not expected to differ between urban areas and nearby rural sites. 


\section{Statistical analyses}

Effects of urbanization and city size on herbivory and leaf traits - We ran linear mixed models (LMMs) testing for the effects of urbanization (urban vs. rural locations), city population size (“city size" hereafter; small, medium and large cities), and their interaction (all fixed factors) on herbivory and plant chemical defences and nutrients (separate models for each group of phenolic compounds and each nutrient). In addition, for each model we also included the effects of country and the country $\times$ city size interaction as random factors in order to analyze the main effects of the split-plot design with the appropriate error terms (Littell et al. 2006). For all models, we used data at the level of sampling location by analysing the mean values across plants within each location. Preliminary analyses including latitude as a covariate indicated no significant association between latitude and any of the response variables measured, and we therefore removed it from the models.

Test of underlying variables associated with urbanization effects on herbivory and plant traits - In those cases where urbanization or city size had significant effects, we again run the above LMMs including effects of urbanization, city size, and their interaction (as fixed factors), as well as covariates potentially associated with (and presumably explaining) such effects on leaf damage and traits. For instance, leaf traits may explain differences in damage such that accounting for them in the herbivory model can inform on whether urbanization effects on insect herbivory were mediated by changes in the plant's phenotype. In the case of herbivory, rather than including all leaf traits in the LMMs which would result in a complex model, we first ran an AIC-based backward stepwise multiple regression including all leaf traits as predictors of leaf damage. Leaf traits retained in this regression model were then used as covariates in the 
herbivory LMMs including the main effects and interaction. In addition to these selected leaf traits, we also included $\mathrm{CO}_{2}$ emissions as a covariate. If $\mathrm{CO}_{2}$ or leaf traits mediate effects of urbanization or city size on herbivory, then significant main effects in the prior models (without covariates) should turn non-significant after including the covariates. We expected $\mathrm{CO}_{2}$ effects on herbivory to be mediated by changes in plant traits associated with insect leaf damage. Therefore, a significant effect of $\mathrm{CO}_{2}$ while accounting for leaf traits would mean that $\mathrm{CO}_{2}$ effects on herbivory are mediated by unmeasured leaf traits or some other mechanism unrelated to changes in plant traits.

In the case of leaf traits, we also re-run LMMs when one or both main effects were significant and also included $\mathrm{CO}_{2}$ as a covariate. We expected direct effects of $\mathrm{CO}_{2}$ on leaf traits based on results from previous work (e.g., increased carbon-based defences such as phenolics as a result of 'excess' $\mathrm{C}$ under elevated $\mathrm{CO}_{2}$; Robinson et al. 2012). Although our goal was to test for effects of urbanization on herbivory via changes in leaf traits, urbanization may affect leaf defences via changes in herbivory (due to plant induced responses). This would be the case if urbanization affected leaf insect herbivory through changes in herbivore activity or predation. In this sense, a positive association between leaf traits and herbivory would suggest that herbivory drives defences (via induction), whereas a negative association suggests defences drive herbivory (Abdala-Roberts et al. 2016a). There were, however, no significant associations between leaf traits and herbivory (see Table SM1 in the Supplementary Material), which precluded reaching either of these interpretations. In addition, herbivory could also influence leaf nutrient concentrations (e.g., through effects on plant vigour or growth), but these traits are usually considered predictors of damage (Carmona et al. 2011) rather than the inverse. We thus did not include damage in the leaf trait models but rather included these traits as covariates in the herbivory models as 
described above.

We performed all LMMs with PROC MIXED in SAS 9.4 (SAS Institute, Cary, NC) (Littell et al. 2006), whereas the stepwise multiple regression for effects of plant traits on herbivory was run with PROC REG. For condensed and hydrolysable tannins, we log-transformed original variables to achieve normality of the residuals. In all cases, we report least-squares means and standard errors as descriptive statistics.

\section{RESULTS}

\section{Effects of urbanization and city size on herbivory and leaf traits}

There was a significant effect of urbanization (urban $v s$. rural locations) on leaf chewer damage, but not on leaf miner abundance (Table 1, Fig. 2). Specifically, we found that leaf chewer damage was, on average, $30 \%$ lower for trees in urban than in rural sampling locations (Fig. 2a). There was no significant effect of city size and no interaction between urbanization and city size on either leaf chewer damage or leaf miner abundance (Table 1, Fig. 2).

Urbanization had a significant effect on the concentration of leaf condensed tannins, hydrolysable tannins, nitrogen and phosphorus, but not on flavonoids or lignins (Table 1). Levels of leaf condensed and hydrolysable tannins were, on average, $36 \%$ and 33\% lower, respectively for trees in urban than in rural sampling locations (Fig. 3c, d), whereas leaf nitrogen and phosphorus were $7 \%$ and $19 \%$ greater, respectively for trees in urban than in rural locations (Fig. 4a, b). City size and the urbanization by city size interaction did not significantly affect any of the studied leaf traits (Table 1, Fig. 3, 4).

Variables associated with urbanization effects on herbivory and plant traits 
Results from the stepwise multiple regression indicated that phosphorous concentration was the only leaf trait retained in the model after backward elimination (slope estimator $[\beta]=-0.0914 \pm 0.0615)$, and we therefore included it as a covariate together with $\mathrm{CO}_{2}$ in the LMM model for leaf chewer damage. Results from the LMM including these covariates indicated that the effect of urbanization on leaf chewer damage remained significant after accounting for $\mathrm{CO}_{2}$ and leaf phosphorus (Table 2), suggesting that unmeasured abiotic factors or plant traits mediated the urbanization effect. The effects of $\mathrm{CO}_{2}$ and phosphorus were not significant (Table 2).

Results from LMMs for leaf traits including $\mathrm{CO}_{2}$ emissions as covariate indicated that the effect of urbanization on leaf condensed and hydrolysable tannins turned non-significant after accounting for $\mathrm{CO}_{2}$ in these models (Table 2), suggesting that this variable mediated urbanization effects on such traits. For both these traits, $\mathrm{CO}_{2}$ levels were significantly negatively associated with compound concentrations (slope estimator $[\beta]$ for condensed tannins $=-0.00023 \pm 0.00011 ; \beta$ for hydrolysable tannins $=$ $-0.00032 \pm 0.00015)$. In contrast, effects of urbanization on leaf nitrogen and phosphorus remained significant after accounting for $\mathrm{CO}_{2}$ (Table 2), suggesting that other unmeasured factors accounted for such effects.

\section{DISCUSSION}

Our results indicated that urbanization significantly affected damage by leaf chewers (but not miners) and leaf traits associated with $Q$. robur. In particular, we found that trees in urban locations exhibited lower levels of leaf-chewing damage and chemical defences (condensed and hydrolysable tannins), and increased levels of leaf nutrients (nitrogen and phosphorus) compared to trees in rural forest locations. In all these cases, the magnitude of these urbanization effects was not contingent upon city size. The fact 
that urbanization significantly affected leaf chewer damage, but not leaf miner abundance, suggests that the effects of urbanization are guild-specific. In addition, effects on leaf defences were accounted for by $\mathrm{CO}_{2}$ emissions, but differences in leaf chewer damage were not associated with changes in either leaf traits or $\mathrm{CO}_{2}$ emission levels. This suggests that effects of urbanization on leaf chewer damage and leaf defences are independent of each other. Overall, these findings illustrate the complex nature of urbanization effects on plant-herbivore interactions and that investigations must account for direct and indirect dynamics operating independently or interactively on plants and insects. In the case of $Q$. robur, our results suggest that urbanization effects may not take place through the bottom-up effects mediated by changes in plant traits envisaged a priori for this species (Moreira et al. 2018), and instead point at alternative direct or indirect mechanisms involving other biotic or abiotic factors which are discussed next.

\section{Effects of urbanization on leaf damage by different insect guilds}

Urbanization significantly decreased leaf chewer damage, and this finding was remarkably consistent across sites throughout most of the geographic distribution of $Q$. robur. The observed reduction in leaf chewer damage in urban sites relative to rural sites contradicts initial work on this subject proposing that herbivory should be higher in urban habitats, presumably because urban conditions limit investment in anti-herbivore defences or weaken predator top-down control of herbivore populations (reviewed by Dreistadt et al. 1990, Raupp et al. 2010). Interestingly, our results are not alone in showing this pattern as a few recent studies have similarly reported decreases in insect herbivory, particularly by leaf chewers, with urbanization (e.g., Herrmann et al. 2012, Bode and Gilbert 2016, Kozlov et al. 2017). Notably, Kozlov et al. (2017) found that 
leaf area loss to insect herbivores was, on average, $16.5 \%$ lower in urban than in rural habitats across 11 tree species in Europe. These recent findings, combined with our results for leaf chewers, support the notion that insect herbivory is lower in urban environments. Nonetheless, it is important to keep in mind that patterns may differ depending on the herbivore species or guild studied. In this sense, we found that, contrary to leaf chewers, leaf miners associated with $Q$. robur were not significantly affected by urbanization. Thus, where effects may be in some cases consistent in magnitude or sign among different guilds (e.g., Kozlov et al. 2017), our results instead suggest differences between insect guilds in susceptibility to changes in abiotic and biotic conditions in urban environments. Such guild-specific responses may reflect changes in species or guild composition which can influence the amount and type of herbivory.

\section{Mechanisms behind urbanization effects on herbivory and leaf traits}

Quercus robur trees located in urban environments exhibited lower levels of leaf defences and higher levels of leaf nutrients, suggesting overall higher plant quality for insect herbivores relative to trees in rural habitats. In addition, observed differences in leaf defence levels between trees in urban vs. rural habitats appeared to be linked to $\mathrm{CO}_{2}$ emission levels, with higher $\mathrm{CO}_{2}$ levels being associated with lower defence levels. These findings contradict work proposing that increased levels of carbon-based defence compounds such as phenolics are a result of the 'excess' $\mathrm{C}$ under elevated $\mathrm{CO}_{2}$ (Robinson et al. 2012). This being said, a meta-analysis including 102 plant species found no clear pattern in the direction of the effect of $\mathrm{CO}_{2}$ levels on plant phenolic compounds (Ryan et al. 2010). Accordingly, a plausible explanation for our findings relies on previous work showing that elevated $\mathrm{CO}_{2}$ levels suppress the production of 
plant hormones such as jasmonic acid and ethylene, which are involved in the synthesis of secondary metabolites (Zavala et al. 2013). Lower levels of leaf chewer damage in urban areas could also explain reduced defences due to weaker herbivore induction, but none of the phenolic compounds studied were found to be associated with herbivory which argues against this (see discussion ahead).

In contrast to chemical defences, differences in leaf nutrient levels were not explained by $\mathrm{CO}_{2}$ emissions, indicating that urbanization affects these leaf traits through some other factor. This finding is in agreement with results of a recent meta-analysis, which found that leaf nitrogen concentrations increase as often as they decrease under elevated $\mathrm{CO}_{2}$ (Ryan et al. 2010). Other unmeasured abiotic factors associated with urbanization such as nitrogen deposition are known to positively influence foliar nitrogen concentration in a number of plant species (Hicks et al. 2000), and may explain changes in this leaf trait. Similarly, elevated levels of phosphorus have often been reported in urban areas due to human activities that result in this nutrient being washed into water bodies (Bouwman et al. 2009).

Despite the effects of urbanization on $Q$. robur leaf traits observed here, changes in leaf chewer damage were not presumably associated with changes in either leaf traits or $\mathrm{CO}_{2}$ emissions. Such a lack of association between damage and plant traits runs counter to our previous work in rural forests with this oak species showing that higher contents of phenolic compounds, particularly condensed tannins, were associated with decreased insect leaf damage (Moreira et al. 2018). There are several non-exclusive explanations for the observed reductions in leaf chewer damage in urban environments. One is that higher temperatures in cities relative to rural habitats (i.e., heat islands) could have direct negative effects on herbivore movement or performance (Bale et al. 2002). However, increases in mean annual temperature between urban and rural habitats 
across the studied region range from 0 to $3.5^{\circ} \mathrm{C}$, a range which does not exceed the thermal safety limit of insect herbivores living in temperate areas (Oke 1973). Indirect effects of temperature on insects via some unmeasured plant trait is also possible, though previous studies in controlled environments reported that increases of $4-6^{\circ} \mathrm{C}$ are necessary to produce detectable changes in plant traits (Zvereva and Kozlov 2006, Bidart-Bouzat and Imeh-Nathaniel 2008). Although these findings suggest that changes in temperature did not mediate urbanization effects on insect herbivores, further work is needed to corroborate this. In addition, it is also possible that changes in some unmeasured abiotic factor directly or indirectly (via some other plant trait) influenced herbivory. The inclusion of other abiotic factors and plant traits is therefore desirable in future work. For instance, Kozlov et al. (2017) found that lower insect herbivory in urban sites was presumably associated with reduced specific leaf area, which is correlated with leaf toughness. Accordingly, measurements of leaf physical or structural traits could be a good candidate to help explain the observed effects of urbanization on insect herbivory.

Increased top-down control by predators could be another explanation for lower herbivory in urban sites. For example, a recent study by Kozlov et al. (2017) reported that increased predation rates by birds and ants in urban (relative to rural) areas were associated with concomitant reductions in damage by insect leaf miners. Similarly, Turrini et al. (2016) found higher predation rates on aphids feeding on Vicia faba growing in urban than in agricultural areas. These findings contradict predictions form ecological theory and contrast with empirical work suggesting weaker top-down regulation of herbivore populations in more simplified communities, which are typical of agricultural, disturbed habitats, or urban environments (Burkman and Gardiner 2014). These recent findings, including our present work, instead suggest that the 
mechanisms driving urbanization effects may lead to alternative outcomes that differ from traditional expectations. Further work is still needed to reach stronger conclusions and a better understanding of underlying mechanisms across a larger number of plant taxa and locations.

\section{Landscape-level factors and urbanization effects on herbivory}

Our findings indicated no effect of city size on either leaf herbivory or leaf traits. This result is somewhat surprising, particularly in the case of plant defences, since $\mathrm{CO}_{2}$ was significantly associated with such traits and gas emissions in large cities were two-fold and 5.5-fold greater (respectively) than in medium-sized and small cities. In addition, the magnitude of differences in $\mathrm{CO}_{2}$ emissions between urban and rural sites associated with large cities was two-fold and six-fold greater (respectively) than the difference for medium-sized and small cities. Such differences in $\mathrm{CO}_{2}$ would have presumably led to an effect of city size on chemical defences, as well as differences in the magnitude of urbanization effects depending on city size. However, there was no interaction between city size and urbanization, suggesting that $\mathrm{CO}_{2}$ levels did not mediate effects of city size on plant defences. To our knowledge, only one previous study by Kozlov et al. (2017) investigated whether city size influences urbanization effects on insect herbivory and plant traits and reported negative effects on leaf herbivory only for sites associated with large cities. Our findings instead suggest that the nature and types of processes driving urbanization effects on herbivory and plant traits remain fundamentally unaltered across urban environments of varying size. Still, we consider that landscape-level factors deserve further attention in comparisons of urban $v s$. rural areas. For example, variables such as the total area covered by vegetation, spatial configuration and connectivity between forested sites in urban areas, or the relative extent of industrial $v s$. residential 
areas may vary independently of city size and influence plant-insect interactions.

\section{Conclusions}

Our simultaneous assessment of insect herbivory, plant traits, and abiotic correlates advances our understanding of the drivers of plant-herbivore interactions in urban environments. Importantly, our results also highlight the asymmetric nature of urbanization effects on different insect herbivore guilds feeding on $Q$. robur. Such effects will result in changes not only in the overall magnitude of damage but also in the predominance of different types of plant-herbivore interactions. In addition, we show that $Q$. robur leaf traits respond to biotic and abiotic conditions in urban environments (e.g., in our case we found an association with $\mathrm{CO}_{2}$ emissions), but such effects may not necessarily trigger bottom-up effects on insect herbivory. Accordingly, phenotypic changes in leaf traits with urbanization appear to be uncoupled from concomitant effects on insect leaf herbivory. Within this context, a key challenge towards understanding how species interactions are modified in urban settings will be to identity the biotic and abiotic factors that (a) exert the strongest controls on interactions and (b) are most affected by urbanization. Knowledge on the direct and indirect mechanisms by which these factors shape species interactions can inform strategies for controlling insect herbivore outbreaks or promoting beneficial interactions in urban environments, restoring ecological communities in degraded habitats adjacent to or within urban areas, as well as designing urban environments that support more diverse or resilient ecological communities.

\section{ACKNOWLEDGEMENTS}

We thank Francisco Pérez, Ana Hernández-Serrano, Teresa Quijano-Medina, Inge van 
Halder and Hervé Jactel for help with field sampling and Rafael Zas for advice with the statistical analyses. This research was financially supported by a Spanish National Research Grant (AGL2015-70748-R), a Regional Government of Galicia Grant (IN607D 2016/001) and the Ramón y Cajal Research Programme (RYC-2013-13230). Author contributions - A. J. M. Tack and B. Castagneyrol share joint last authorship

\section{REFERENCES}

Abdala-Roberts, L., et al. 2016a. Test of biotic and abiotic correlates of latitudinal variation in defenses in the perennial herb Ruellia nudiflora. - J. Ecol. 104: 580590.

Abdala-Roberts, L., et al. 2016b. Biotic and abiotic factors associated with altitudinal variation in plant traits and herbivory in a dominant oak species. - Am. J. Bot. 103: 2070-2078.

Bale, J. S., et al. 2002. Herbivory in global climate change research: direct effects of rising temperature on insect herbivores. - Glob. Change Biol. 8: 1-16.

Beninde, J., et al. 2015. Biodiversity in cities needs space: A meta-analysis of factors determining intra-urban biodiversity variation. - Ecol. Lett. 18: 581-592.

Bidart-Bouzat, M. G. and Imeh-Nathaniel, A. 2008. Global change effects on plant chemical defenses against insect herbivores. - J. Integr. Plant Biol. 50: 1339-1354.

Bode, R. F. and Gilbert, A. B. 2016. Seed predators, not herbivores, exert natural selection on Solidago spp. in an urban archipelago. - Environ. Entomol. 45: 150154.

Bouwman, A. F., et al. 2009. Human alteration of the global nitrogen and phosphorus soil balances for the period 1970-2050. - Global Biogeochem. Cycles 23: GB0A04. 
Burkman, C. E. and Gardiner, M. M. 2014. Urban greenspace composition and landscape context influence natural enemy community composition and function. - Biol. Cont. 75: 58-67.

Carmona, D., et al. 2011. Plant traits that predict resistance to herbivores. - Funct. Ecol. 25: $358-367$.

Castagneyrol, B., et al. 2013. Plant apparency, and overlooked driver of associational resistance to insect herbivory. - J. Ecol. 101: 418-429.

Castagneyrol, B., et al. 2012. Genetic diversity increases insect herbivory on oak saplings. - PLoS ONE 7: e44247.

Cuevas-Reyes, P., et al. 2013. Patterns of herbivory and fluctuating asymmetry in Solanum lycocarpum St. Hill (Solanaceae) along an urban gradient in Brazil. Ecol. Indicat. 24: 557-561.

Dreistadt, S. H., et al. 1990. Urban forests and insect ecology. - BioScience 40: 192-198.

El-Sabaawi, R. 2018. Trophic structure in a rapidly urbanizing planet. — Funct. Ecol. 32: 1718-1728.

Feeny, P. 1970. Seasonal changes in oak leaf tannins and nutrients as a cause of spring feeding by winter moth caterpillars. - Ecology 51: 565-581.

Forkner, R. E. and Hunter, M. D. 2000. What goes up must come down? nutrient addition and predation pressure on oak herbivores. - Ecology 81: 1588-1600.

Giffard, B., et al. 2012. Influence of surrounding vegetation on insect herbivory: A matter of spatial scale and herbivore specialisation. - Basic Appl. Ecol. 13: 458-465.

Hahs, A. K., et al. 2009. A global synthesis of plant extinction rates in urban areas. Ecol. Lett. 12: 1165-1173.

Herrmann, D. L. et al. 2012. Drivers of specialist herbivore diversity across 10 cities Landsc. Urban Plan. 108: 123-130. 
Hicks, W. K., et al. 2000. Can the foliar nitrogen concentration of upland vegetation be used for predicting atmospheric nitrogen deposition? Evidence from field surveys. - Environ. Pollut. 107: 367-376.

Huberty, A. F. and Denno, R. F. 2006. Consequences of nitrogen and phosphorus limitation for the performance of two planthoppers with divergent life-history strategies. - Oecologia 149: 444-455.

Johnson, M. T. J. and Munshi-South, J. 2017. Evolution of life in urban environments. Science 358: eaam8327.

Kozlov, M. V., et al. 2017. Decreased losses of woody plant foliage to insects in large urban areas are explained by bird predation. - Glob. Change Biol.: 4354-4364.

Lambert, M. R., et al. 2015. Suburbanization, estrogen contamination, and sex ratio in wild amphibian populations. - Proc. Natl. Acad. Sci. USA 112: 11881-11886.

Littell, R. C., et al. 2006. SAS System for mixed models, second edition. Cary, NC.

Mattson, W. J. 1980. Herbivory in relation to plant nitrogen content. - Annu. Rev. Ecol. System. 11: 119-161.

McDonnell, M. J. and Pickett, S. T. A. 1990. Ecosystem structure and function along urban-rural gradients: an unexploited opportunity for ecology. - Ecology 71: $1232-1237$.

McDonnell, M. J., et al. 1997. Ecosystem processes along an urban-to-rural gradient. Urb. Ecosyst. 1: 21-36.

Mithöfer, A. and Boland, W. 2008. Recognition of herbivory-associated molecular patterns. - Plant Physiol. 146: 825-831.

Moreira, X., et al. 2018. Latitudinal variation in plant chemical defenses drives latitudinal patterns of leaf herbivory. - Ecography 41: 1124-1134. 
Moreira, X., et al. 2017. Interactive effects of plant neighbourhood and ontogeny on insect herbivory and plant defensive traits. - Sci. Rep. 7: 4047.

Moreira, X., et al. 2014. Trade-offs between constitutive and induced defences drive geographical and climatic clines in pine chemical defences. - Ecol. Lett. 17: 537546.

Moreira, X., et al. 2012. Genetic variation and phenotypic plasticity of nutrient reallocation and increased fine root production as putative tolerance mechanisms inducible by methyl-jasmonate in pine trees. - J. Ecol. 100: 810-820.

Oda, T., et al. 2018. The Open-source Data Inventory for Anthropogenic $\mathrm{CO}_{2}$, version 2016 (ODIAC2016): a global monthly fossil fuel $\mathrm{CO}_{2}$ gridded emissions data product for tracer transport simulations and surface flux inversions. - Earth Syst. Sci. Data 10: 87-107.

Oke, T. R. 1973. City size and urban heat island. - Atmospheric Environment 7: 769-779.

Petit, R. J., et al. 2002. Range wide distribution of chloroplast DNA diversity and pollen deposits in European white oaks: inferences about colonisation routes and management of oak genetic resources. - For. Ecol. Manage. 156: 49-74.

Raupp, M. J., et al. 2010. Ecology of herbivorous arthropods in urban landscapes. Annu. Rev. Entomol. 55: 19-38.

Robinson, E. A., et al. 2012. A meta-analytical review of the effects of elevated $\mathrm{CO}_{2}$ on plant-arthropod interactions highlights the importance of interacting environmental and biological variables. - New Phytol. 194: 321-336.

Roslin, T. and Salminen, J. P. 2008. Specialization pays off: contrasting effects of two types of tannins on oak specialist and generalist moth species. - Oikos 117: 15601568. 
Ryan, G. D., et al. 2010. Global atmospheric change and trophic interactions: are there any general responses? - In: Baluska, F. and Ninkovic, V. (eds.), Plant communication from an ecological perspective. pp. 179-214. Springer-Verlag, Berlin, Germany.

Salminen, J.-P. and Karonen, M. 2011. Chemical ecology of tannins and other phenolics: we need a change in approach. - Funct. Ecol. 25: 325-338.

Salminen, J. P., et al. 2004. Seasonal variation in the content of hydrolyzable tannins, flavonoid glycosides, and proanthocyanidins in oak leaves. - J. Chem. Ecol. 30: 1693-1711.

Searle, S. Y. et al. 2012. Urban environment of New York City promotes growth in northern red oak seedlings. — Tree Physiol. 32: 389-400.

Southwood, T. R. E., et al. 2005. The composition of the arthropod fauna of the canopies of some species of oak (Quercus). - Eur. J. Entomol. 102: 65-72.

Stam, J. M., et al. 2014. Plant interactions with multiple insect herbivores: From community to genes. - Annu. Rev. Plant Biol. 65: 689-713.

Stiling, P. and Cornelissen, T. 2007. How does elevated carbon dioxide $\left(\mathrm{CO}_{2}\right)$ affect plant-herbivore interactions? A field experiment and meta-analysis of $\mathrm{CO}_{2}-$ mediated changes on plant chemistry and herbivore performance. - Glob. Change Biol. 13: 1823-1842.

Tack, A. J. M., et al. 2010. Spatial location dominates over host plant genotype in structuring an herbivore community. - Ecology 91: 2660-2672.

Tack, A. J. M. and Roslin, T. 2011. The relative importance of host-plant genetic diversity in structuring the associated herbivore community. - Ecology 92: 15941604. 
Thompson, K. A., et al. 2016. Urbanization drives the evolution of parallel clines in plant populations. - Proc. Roy. Soc. B 283: 20162180.

Turcotte, M. M., et al. 2014. Macroecological and macroevolutionary patterns of leaf herbivory across vascular plants. - Proc. Roy. Soc. B 281: 20140555.

Turrini, T., et al. 2016. Effects of urbanization on direct and indirect interactions in a tritrophic system. - Ecol. Appl. 26: 664-675.

United Nations Department of Economics and Social Affairs. 2014. 2014 World urbanization prospects: the 2014 revision, highlights (ST/ESA/SER.A/352). -.

Walinga, I., et al. 1995. Plant analysis manual. - Kluwer Academic Publisher. Dordrecht, The Netherlands.

Youngsteadt, E. et al. 2015. Habitat and species identity, not diversity, predict the extent of refuse consumption by urban arthropods. - Glob. Change Biol. 21: 11031115

Zavala, J. A., et al. 2013. An emerging understanding of mechanisms governing insect herbivory under elevated $\mathrm{CO}_{2}$. - Annu. Rev. Entomol. 58: 79-97.

Zvereva, E. L. and Kozlov, M. V. 2006. Consequences of simultaneous elevation of carbon dioxide and temperature for plant-herbivore interactions: a metaanalysis. Glob. Change Biol. 12: 27-41. 


\section{FIGURE LEGENDS}

Figure 1. Maps for emissions of $\mathrm{CO}_{2}$ in petagrams of carbon (log-transformed)

including a spatial layout of the cities where we sampled rural and urban locations with

Quercus robur $(\mathrm{N}=18$ cities $)$. The size of the circle indicates the size of the city

population: small: 21,000-46,000 inhabitants; medium-sized: 152,000-292,000

inhabitants; large: >1,000,000 inhabitants.

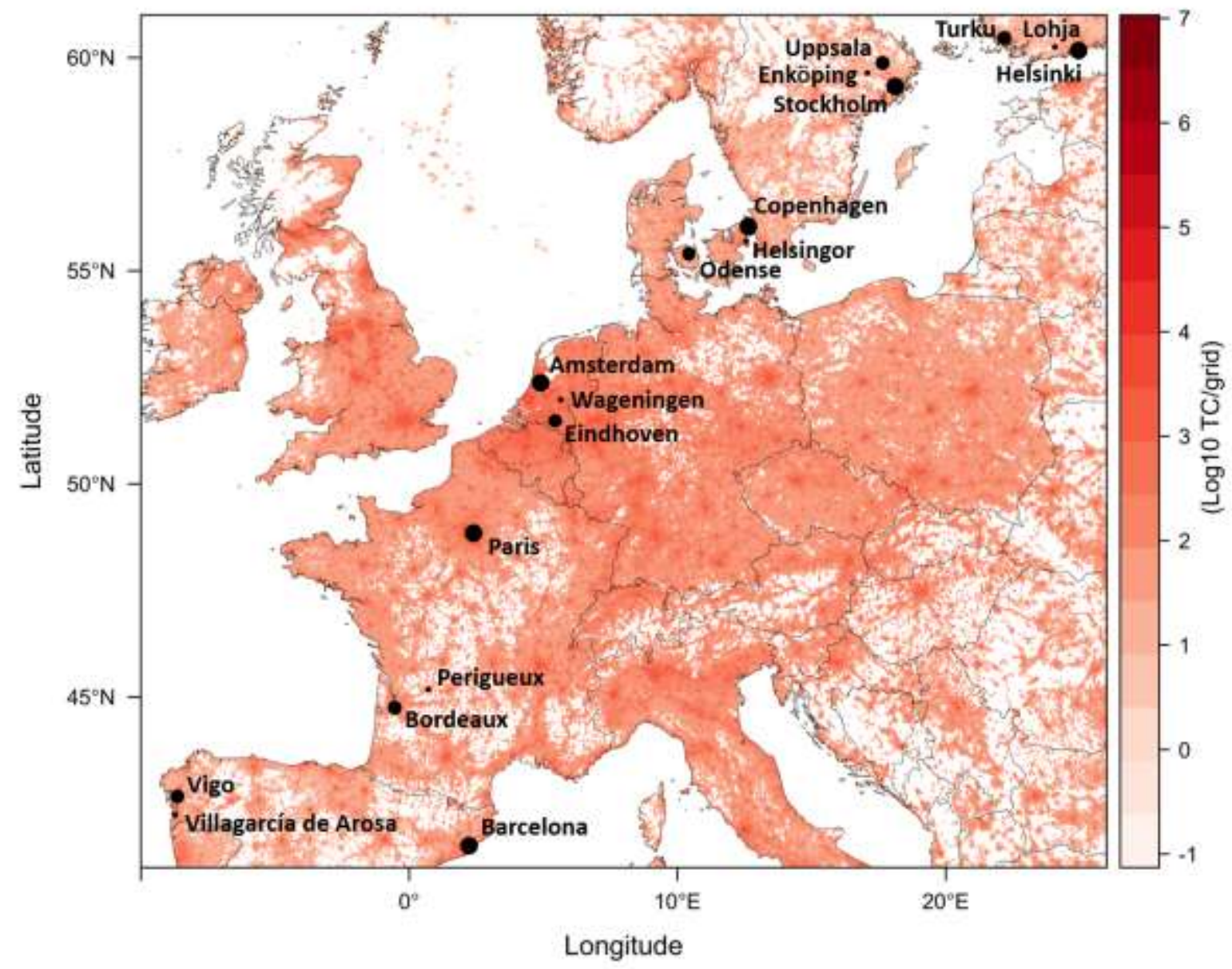

'This article is protected by copyright. All rights reserved.' 
Figure 2. (a) Leaf chewer damage and (b) leaf miner abundance in Quercus robur trees growing in urban (grey bars) and rural (white bars) habitats of large, medium and small cities. Leaf chewer damage was visually estimated using an ordinal scale based on the percentage of leaf area removed. Leaf miner abundance was measured by counting mines on each leaf and used the number of mines per 25 leaves. Bars are least square means \pm standard error $(\mathrm{N}=6)$. Results of the linear mixed models are presented in Table 1.

(a)
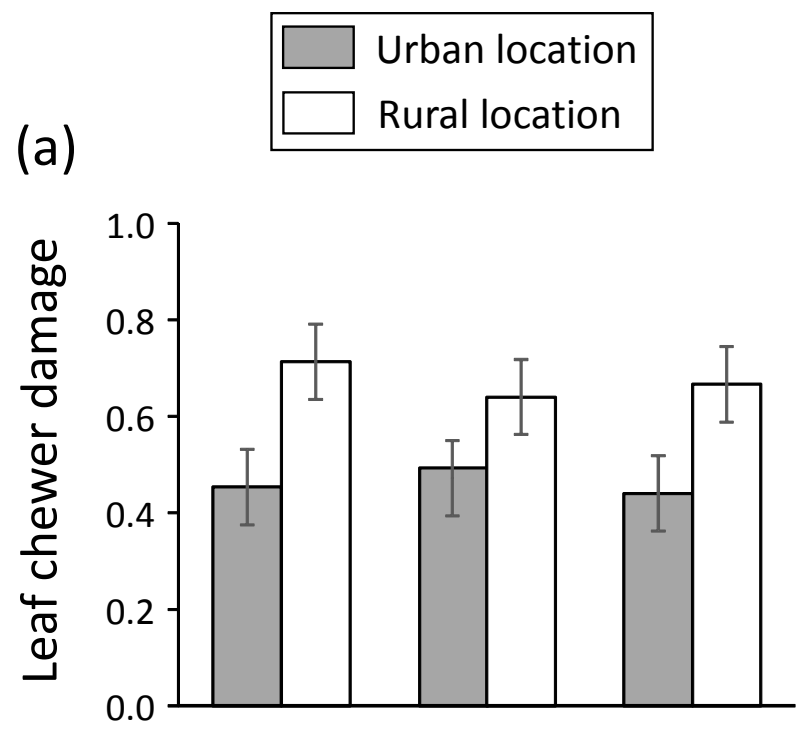

(b)

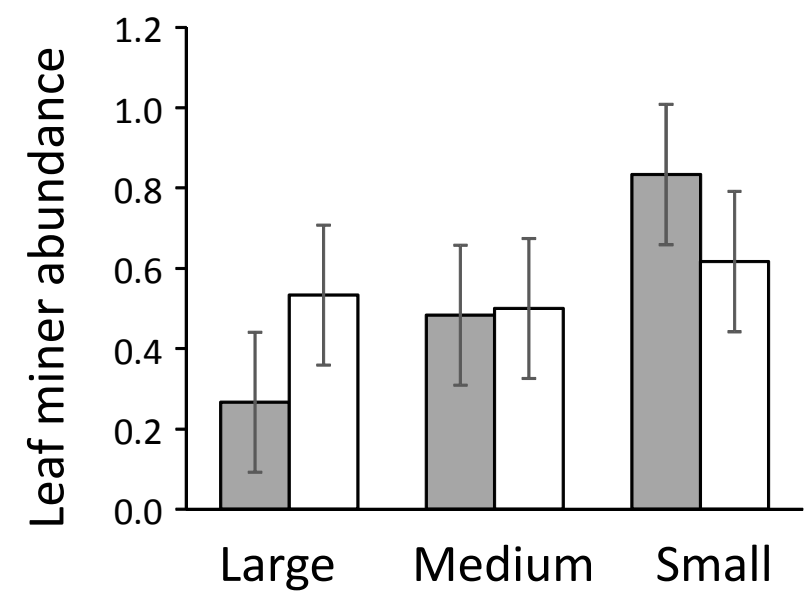

City size 
Figure 3. Concentration (in $\mathrm{mg} \mathrm{g}^{-1} \mathrm{~d}$.w.) of (a) flavonoids, (b) lignins, (c) condensed tannins and (d) hydrolysable tannins in leaves of Quercus robur trees growing in urban (grey bars) and rural (white bars) habitats of large, medium and small cities. Bars are least square means \pm standard error $(\mathrm{N}=6)$. Results of the linear mixed models are presented in Table 1.

\begin{tabular}{l}
$\square$ Urban location \\
$\square$ Rural location \\
\hline
\end{tabular}
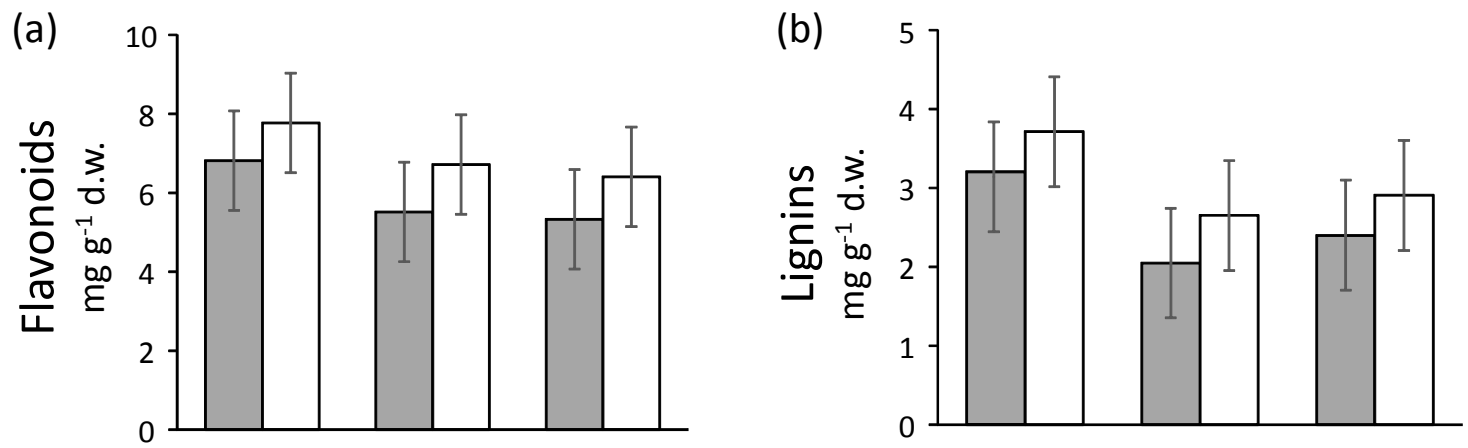

(c)

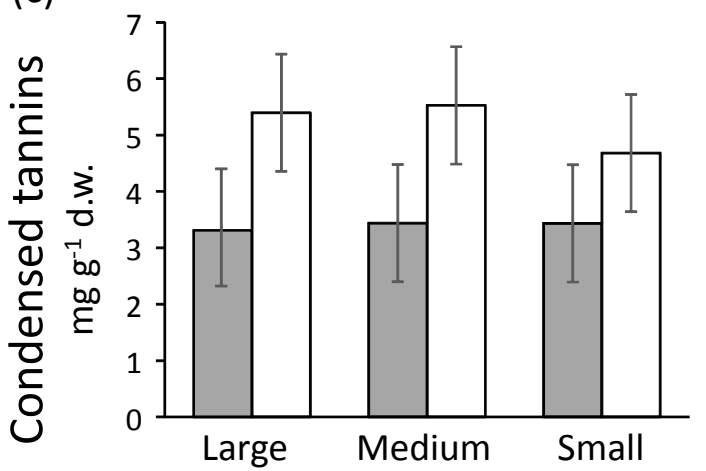

City size
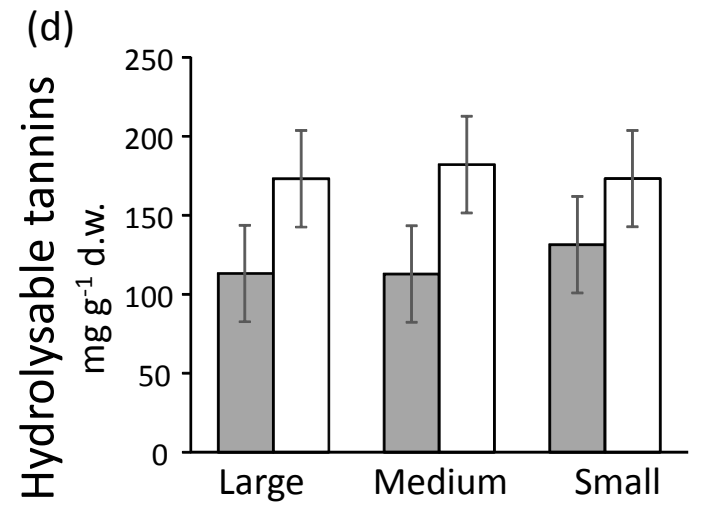

City size 
Figure 4. Concentration (in $\mathrm{mg} \mathrm{g}^{-1} \mathrm{~d}$.w.) of (a) nitrogen and (b) phosphorus in leaves of Quercus robur trees growing in urban (grey bars) and rural (white bars) habitats of large, medium and small cities. Bars are least square means \pm standard error $(\mathrm{N}=6)$. Results of the linear mixed models are presented in Table 1.

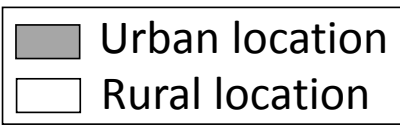

(a)

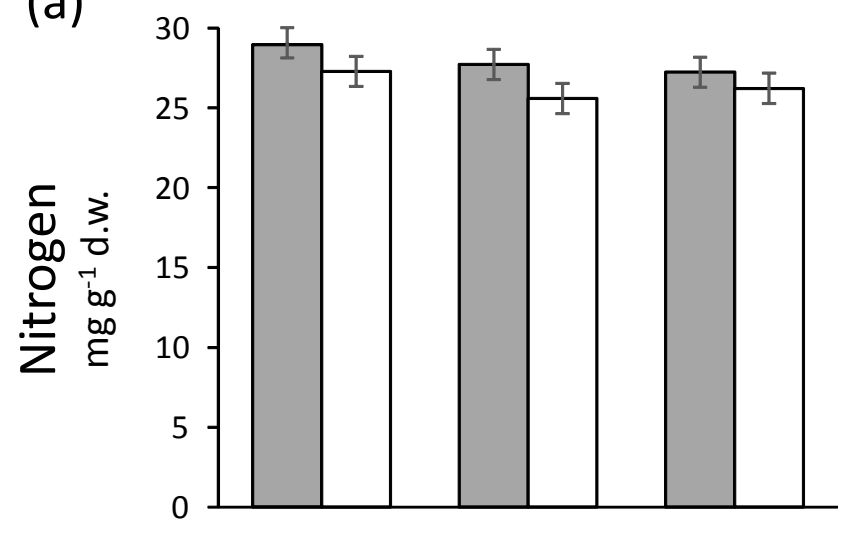

(b)

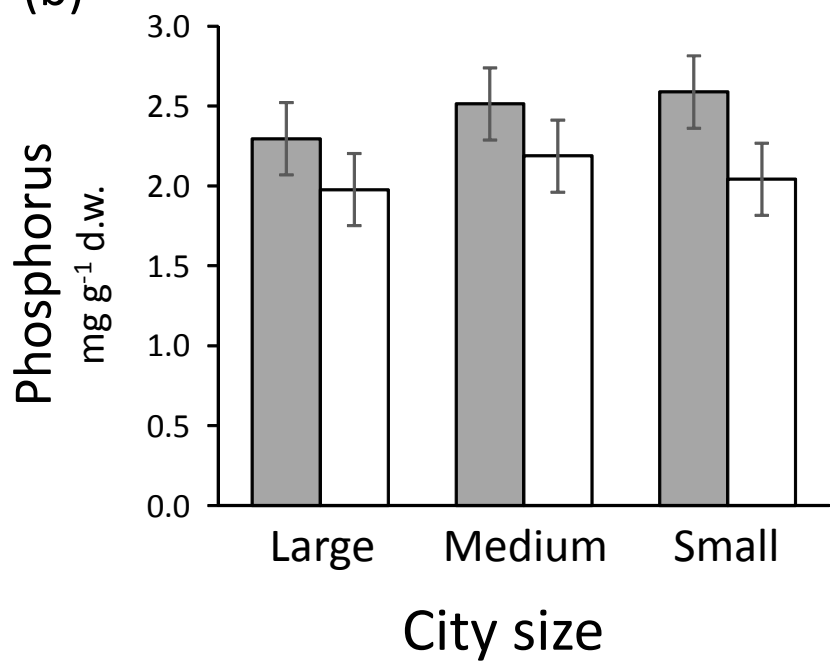

'This article is protected by copyright. All rights reserved.' 


\section{Table Legends}

Table 1. Summary of results from linear mixed models testing for the effects of urbanization (urban vs. rural habitats), city size (large, medium and small) and their interaction on leaf damage by chewing insects, leaf miner abundance, and concentration of leaf chemical defences (flavonoids, lignins, condensed tannins, and hydrolysable tannins) and nutrients (nitrogen and phosphorus) for Quercus robur trees. In all cases, we used the mean value across plants within each sampling location (see sampling design in the Methods). F-values with degrees of freedom (numerator, denominator) and associated significance levels $(P$-values $)$ are shown. Significant $P$-values $(\mathrm{P}<0.05)$ are highlighted in bold face.

\begin{tabular}{lcccccc} 
& \multicolumn{2}{c}{ Urbanization $(\mathrm{U})$} & \multicolumn{2}{c}{ Size $(\mathrm{S})$} & \multicolumn{2}{c}{$\mathrm{U} \times \mathrm{S}$} \\
\hline & $\mathrm{F}_{1,15}$ & $P$-value & $\mathrm{F}_{2,10}$ & $P$-value & $\mathrm{F}_{2,15}$ & $P$-value \\
\hline Chewer damage & 10.66 & $\mathbf{0 . 0 0 5}$ & 0.08 & 0.924 & 0.37 & 0.696 \\
Miner abundance & 0.04 & 0.846 & 2.97 & 0.097 & 1.54 & 0.246 \\
Flavonoids & 4.18 & 0.059 & 1.12 & 0.364 & 0.02 & 0.982 \\
Lignins & 3.74 & 0.072 & 2.20 & 0.162 & 0.01 & 0.990 \\
Condensed tannins & 12.62 & $\mathbf{0 . 0 0 3}$ & 0.11 & 0.899 & 0.40 & 0.675 \\
Hydrolysable tannins & 8.74 & $\mathbf{0 . 0 1 0}$ & 0.30 & 0.751 & 0.28 & 0.757 \\
Nitrogen & 8.07 & $\mathbf{0 . 0 1 2}$ & 0.87 & 0.449 & 0.32 & 0.731 \\
Phosphorus & 9.33 & $\mathbf{0 . 0 0 8}$ & 1.02 & 0.395 & 0.33 & 0.724 \\
\hline
\end{tabular}


Table 2. Summary of results from linear mixed models testing for the effects of urbanization (urban vs. rural habitats), city size (large, medium and small), and their interaction on leaf damage by leaf chewing insects and concentration of condensed tannins, hydrolysable tannins, nitrogen and phosphorus in leaves of Quercus robur trees. For all models, we included $\mathrm{CO}_{2}$ emissions as a covariate to test if urbanization effects on herbivory and leaf traits were determined by this abiotic factor. For the model of chewer damage, we also included phosphorus as a covariate to test if urbanization effects on herbivory were indirectly mediated by changes in this leaf trait. In all cases, we used the mean value across plants within each sampling location. F-values with degrees of freedom (numerator, denominator) and associated significance levels are shown. Significant $P$-values $(\mathrm{P}<0.05)$ are in bold.

\begin{tabular}{lccccccccccc}
\hline \multirow{2}{*}{ Response variable } & \multicolumn{2}{c}{ Urbanization $(\mathrm{U})$} & \multicolumn{2}{c}{ City size $(\mathrm{S})$} & \multicolumn{2}{c}{$\mathrm{U} \times \mathrm{S}$} & \multicolumn{2}{c}{$\mathrm{CO}_{2}$ emission } & \multicolumn{2}{c}{ Phosphorus } \\
\cline { 2 - 12 } & $\mathrm{F}_{1,13}$ & $P$ & $\mathrm{~F}_{2,13}$ & $P$ & $\mathrm{~F}_{2,13}$ & $P$ & $\mathrm{~F}_{1,13}$ & $P$ & $\mathrm{~F}_{1,13}$ & $P$ \\
\hline Chewer damage & 5.33 & 0.038 & 0.02 & 0.980 & 0.37 & 0.699 & 0.07 & 0.798 & 0.12 & 0.737 \\
\hline & & & & & & & & & & - \\
\cline { 2 - 13 } & $\mathrm{F}_{1,14}$ & $P$ & $\mathrm{~F}_{2,14}$ & $P$ & $\mathrm{~F}_{2,14}$ & $P$ & $\mathrm{~F}_{1,14}$ & $P$ & & - \\
\hline Condensed Tannins & 1.26 & 0.281 & 0.52 & 0.608 & 0.14 & 0.873 & 4.76 & $\mathbf{0 . 0 4 6}$ & - & - \\
Hydrolysable Tannins & 0.61 & 0.449 & 0.28 & 0.759 & 0.37 & 0.696 & 4.69 & $\mathbf{0 . 0 4 8}$ & - & - \\
Nitrogen & 4.81 & $\mathbf{0 . 0 4 6}$ & 0.86 & 0.453 & 0.49 & 0.622 & 0.21 & 0.658 & - & - \\
Phosphorus & 5.61 & $\mathbf{0 . 0 3 3}$ & 0.49 & 0.628 & 0.16 & 0.857 & 0.00 & 0.964 & - & - \\
\hline
\end{tabular}

